\title{
Hypocalcemic vitamin D-dependent rickets
}

INSERM

\section{Source}

INSERM. (1999). Orphanet: an online rare disease and orphan drug data base.

Hypocalcemic vitamin D-dependent rickets. ORPHA:289157

Hypocalcemic vitamin D-dependent rickets (VDDR-I) is an early-onset hereditary vitamin

D metabolism disorder characterized by severe hypocalcemia leading to osteomalacia and rachitic bone deformations, and moderate hypophosphatemia. 